\title{
Remidiasi Miskonsepsi Siswa Pada Materi Listrik Dinamis Menggunakan Ebook Interaktif
}

\author{
Mukhlis Hidayatulloh $^{1}$, Iskandar Wiryokusumo², Djoko Adi Walujo ${ }^{2}$ \\ ${ }^{1}$ Program Studi Teknologi Pendidikan, Program Pascasarjana, Universitas PGRI Adi Buana \\ Surabaya \\ ${ }^{2}$ Teknologi Pendidikan, Program Pascasarjana, Universitas PGRI Adi Buana Surabaya \\ *Email: hidayatullohmukhlis027@gmail.com
}

DOI: http://dx.doi.org/10.29303/jpft.v5i1.986

\begin{abstract}
Based on previous research, student had many misconceptions occurred in dynamic electrical material so the researcher developed interactive ebook of dynamic electrical material which was integrated with PhET simulation software to reduce misconception on that material. The purposes of this study are: (1) Describe the validity of an interactive ebook based on expert assessment in terms of material, media, and language and three physics teachers; (2) Describe the effectiveness of interactive ebook based on the decrease of student misconception after learning with developed ebook; and (3) Describe the practicality of the ebook based on the student response questionnaire. The method used in ebook development refers to Instructional Design Strategy developed by Moore \& Kearsley with sequence: Analysis, Design, Development, Implementation, and Evaluations. The results of this study are: (1) Development of an interactive ebook is in a very decent category in terms of validity from expert assessment on material, media, and language ebook and three physics teachers; (2) The effectiveness of interactive ebook is in the effective category, it could reduce student misconceptions on dynamic electrical materials effectively; and (3) The developed ebook are very practical to use, responses of students were positively.
\end{abstract}

Keywords: Ebook, Misconception, Dynamic Electrical

PENDAHULUAN

Kurikulum Tingkat Satuan

Pendidikan (KTSP) dan Kurikulum 2013 menekankan pentingnya pembelajaran yang berpusat pada siswa, sehingga didapatkan pembelajaran terbaik, yaitu dengan membatasi waktu guru menyampaikan materi, memberikan banyak waktu untuk aktivitas siswa sehingga secara otomatis siswa mendapatkan pengalaman belajar. Guru mengajak siswa untuk menemukan materi dan manfaat nyata dari kegiatan belajarnya sehingga mereka merasa mempunyai kemampuan untuk mandiri dalam menemukan konsepnya.

Namun, penerapan pembelajaran berpusat pada siswa masih ditemui berbagai kesulitan dalam prosesnya. Siswa kesulitan mempelajari materi listrik dinamis karena penguasaan konsep yang kurang, kemampuan matematika yang rendah, dan kesalahan dalam mengubah satuan karena kemampuan siswa yang rendah dalam hal: verbal, menggunakan skema untuk memahami suatu informasi, dan membuat strategi pemecahan masalah (Rusilowati, 2006) (Pitterson \& Streveler, 2016).

Dengan berbagai macam perubahan dan revisi Kurikulum 2013 masih ditemukan berbagai penelitian yang mengungkap miskonsepsi siswa pada materi listrik dinamis. Konsep listrik dinamis terdiri dari konsep: arus, beda potensial, dan rangkaian listrik tertutup, mendapatkan $39,9 \%$ siswa mengalami miskonsepsi dan $44,01 \%$ siswa berpeluang tidak memahami konsep (Ismail et al. 2015). Profil miskonsepsi materi listrik dinamis dengan kriteria tinggi pada bahasan Hukum Kirchhoff dan energi serta daya hantar listrik. Sedangkan untuk sub pokok bahasan dengan profil kesulitan dengan kriteria cukup tinggi yaitu pada sub pokok bahasan: 1) Hukum Ohm dan hambatan suatu konduktor arus, tegangan, dan hambatan listrik; 2) rangkaian resistor seri dan paralel dengan faktor kesulitan 
kurangnya minat dan motivasi belajar siswa dan kurangnya variasi metode pembelajaran (Sihombing \& Novitasari, 2017). Siswa lebih suka belajar fisika dengan menghafal tanpa memahami konsep materi. Selain itu, dalam pembelajaran fisika, pembelajaran untuk memecahkan masalah dilakukan tanpa pemahaman yang mendalam (Hartono et al. 2017). Miskonsepsi dapat berkembang setelah terjadi proses belajar. Miskonsepsi ini mempengaruhi pemahaman siswa, karena mereka menafsirkan penjelasan guru dalam kesalahpahaman. Siswa yang mempelajari ilmu fisika akan terus menggunakan konsep serupa dari tahun ke tahun. Jika siswa memiliki kesalahpahaman terkait dengan konsep-konsep ini selama belajar, mereka mentransfer miskonsepsinya ke tingkat berikutnya (Turgut et al. 2012). Guru harus memutuskan sendiri mengenai teknik apa yang digunakan, media apa yang digunakan, dan bagaimana menggunakan teknik dan media tersebut, termasuk untuk meremidiasi miskonsepsi materi listrik dinamis. Diperlukan teori serta hasil penelitian sebelumnya yang patut dicoba dan diterapkan di kelas sebagai suatu solusi akan hal tersebut.

Teori belajar konstruktivis menekankan bahwa pentingnya belajar agar siswa membangun sendiri pengalaman belajarnya untuk memaknai materi. Namun, diperlukan perancah yang sesuai untuk membantu siswa membangun kerangka mental tentang konsep.

Di era modern, peran multimedia dalam pembelajaran dapat membatu siswa dalam penguasaan konsep. Kelas yang menggunakan bantuan multimedia mengalami peningkatan penguasaan konsep yang lebih baik dibandingkan dengan kelas tanpa bantuan multimedia (Sugiana et al. 2016). Pada topik besaran pokok dan turunan penguasaan konsep fisika peserta didik, dengan bantuan multimedia interaktif meningkat secara maksimal yaitu $100 \%$ (Yulianci et al. 2017).

Salah satu multimedia pembelajaran yang dapat menanamkan konsep pembelajaran sains adalah perangkat lunak PhET. PhET dalam penelitian terakhir telah berfokus untuk membantu siswa membangun pemahaman konseptual dari sains (Adams, 2010). Pembelajaran fisika dengan bantuan PhET menjadi salah satu strategi berbasis penelitian terbaik untuk mengenalkan pemahaman konseptual, ada banyak manfaat menggunakan teknologi $\mathrm{PhET}$ dikombinasikan dengan strategi berbasis penelitian dalam mempengaruhi pemahaman siswa ke tingkat lebih dalam (Quezada et al. 2015). Hal ini terbukti bahwa pembelajaran dengan menggunakan model discovery learning berbantuan media PhET berpengaruh positif terhadap hasil belajar (Lidiana et al. 2018).

Kegiatan mandiri membantu dalam meningkatkan hasil belajar secara efektif dibandingkan dengan metode ceramah, demonstrasi, atau diskusi (Hackathorn et al, 2011). Namun model inkuiri yang merupakan salah satu teknik pembelajaran siswa aktif hanya mampu meremidiasi miskonsepsi siswa secara signifikan hanya pada sub bahasan rangkaian seri saja (Fajar \& Supardi, 2013). Selain itu pembelajaran Kurikulum 2013 dengan pendekatan saintifik hanya mereduksi miskonsepsi siswa pada materi listrik dinamis dengan kriteria rendah hingga sedang (Hidayatulloh et al. 2015).

Munculnya budaya literasi dalam Kurikulum 2013 karena kompetensi membaca siswa Indonesia yang rendah serta belum membudaya tentang gerakan gemar membaca. Capaian rata-rata kemampuan membaca siswa Indonesia berada pada level rendah di bawah median internasional (Suryaman, 2015). Simulasi komputer dapat dijadikan alternatif dalam pembelajaran. Namun, dalam penerapannya memerlukan perencanaan dan persiapan yang matang 
sebelum diterapkan di kelas agar proses pembelajaran dapat berjalan sesuai dengan tujuan pembelajaran yang hendak dicapai (Niami et al. 2018). Salah satu solusi untuk meningkatkan minat baca dan perencaaan pembelajaran yang terstruktur dengan membuat buku yang menarik dan kekinian. Salah satunya dengan ebook yang interaktif, disesuaikan dengan kebutuhan siswa, menawarkan konsep inovatif yang dapat diperluas dan ditingkatkan dalam berbagai macam cara yang adaptif bagi siswa (Dingli \& Cachia, 2014).

Pengembangan ebook interaktif pada mata pelajaran fisika sejauh ini tidak mengalami masalah dan terus berkembang. Penelitian pengembangan ebook pada materi kalor, berdasarkan penilaian yang telah dilakukan berdasarkan uji validitas ahli dan respons siswa, media ebook interaktif bilingual yang dikembangkan layak digunakan sebagai media pembelajaran untuk siswa serta mampu menurunkan miskonsepsi siswa (Darlen et al. 2015) (Istifarida et al. 2017).

Berdasarkan paparan di atas, didapatkan keterangan bahwa: 1) Penelitian mengenai miskonsepsi siswa dalam materi listrik dinamis masih berkembang dengan berbagai alternatif solusi; 2) Remidiasi miskonsepsi listrik dinamis menggunakan perangkat lunak PhET dengan metode pembelajaran tertentu; dan 3) Literasi siswa Indonesia yang relatif rendah, perlu adanya ebook yang interaktif bagi siswa. Hal tersebut mendasari sebuah penelitian yang bertujuan mengembangkan ebook interaktif untuk meremidiasi miskonsepsi siswa pada materi listrik dinamis yang layak berdasarkan validitas penilaian ahli, kepraktisan berdasarkan analisis respons siswa, dan efektifitas berdasarkan penurunan kesalahan konsep.

Ebook interaktif yang dikembangkan dibuat dengan perangkat lunak Flipbuilder, sehingga terbentuk seperti buku tiga dimensi yang dapat dibalik-balik. Terdapat video dan gambar menarik berkaitan dengan materi yang akan dipelajari, video tutorial praktis tentang bagaimana melakukan praktikum menggunakan perangkat lunak PhET Simulation yang dihasilkan dari Camtasia Studio 7, untuk setiap praktikum yang akan dilakukan siswa. Kuis yang terkait dengan materi yang dibahas dibuat dengan perangkat lunak ISpring dengan musik yang penuh semangat pada setiap soalnya.

\section{METODE PENELITIAN}

Penelitian pengembangan ini menggunakan model Instructional Design Strategy yang dikembangkan oleh Moore \& Kearsley (2012) dengan tahapan analisis, perancangan, pengembangan, implementasi, dan evaluasi.

Penelitian dilakukan pada 40 siswa kelas XII MIA SMA Progresif Bumi Shalawat Sidoarjo tahun ajaran 2017/2018. Instrumen yang digunakan adalah: lembar validasi materi, media, dan bahasa; angket respons siswa; dan lembar tes.

\section{A. Tahap Analisis}

Pada tahap ini dilakukan analisis kebutuhan, identifikasi masalah, dan analisis tugas penelitian, sehingga didapatkan dasardasar rancangan ebook.

\section{B. Tahap Perancangan}

Pada tahap ini dirumuskan tujuan pembelajaran, pengembangan butir tes standar yang diadaptasi dari Determining and Interpreting Resistive Electric Circuit Concepts Test Version 1.2 (DIRECT V 1.2) yang dibuat oleh Engelhardt dan Beichner (2013). Rencana pelaksanaan pembelajaran dibuat khusus untuk meremidiasi miskonsepsi berdasarkan jawaban tes awal siswa sehingga pembelajaran tepat sasaran. Selanjutnya, dilakukan identifikasi sumber belajar untuk menghasilkan rancangan awal, sehingga menghasilkan ebook draf I. 


\section{Tahap Pengembangan}

Pada tahap ini, membuat ebook dibuat berdasarkan tahap analisis dan perancangan. Ebook yang dikembangkan dinilai oleh validator ahli materi, media, dan bahasa serta tiga guru fisika untuk ditentukan validitasnya (Hartini et al. 2017). Rata-rata hasil penilaian validator ditentukan oleh persentase dan kategori menurut Tabel 1.

Tabel 1 Kategori validitas ebook

\begin{tabular}{cc}
\hline Persentase (\%) & Kategori \\
\hline $0-20$ & Sangat lemah \\
\hline $21-40$ & Lemah \\
\hline $41-60$ & Cukup \\
\hline $61-80$ & layak \\
\hline $81-100$ & Sangat layak \\
\hline & (Hartini et al. 2017)
\end{tabular}

\section{Tahap Implementasi}

Pada tahap ini menggunakan onegroup pretest-posttest design yaitu sebuah sampel kelas diberikan tes awal (pretes) untuk mengetahui pengetahuan awal siswa. Setelah mendapatkan data tersebut, peneliti memberikan perlakuan berupa pembelajaran menggunakan ebook draf II. Kemudian diberikan tes sesudah perlakuan (postes).

\section{$\mathrm{O}_{1} \longrightarrow \mathrm{X} \longrightarrow \mathrm{O}_{2}$}

Gambar 1 One group pretest post-test design (Cranmer, 2017)

Dari pre-test dan post-test, profil konsepsi siswa dianalisis menggunakan nilai CRI (Certainty of Response Index) dan jawaban siswa.

Tabel 1. Kriteria CRI (Hasan et al, 1999)

\begin{tabular}{cl}
\hline CRI & \multicolumn{1}{c}{ Criteria } \\
\hline 1 & Almost guess \\
\hline 2 & Not Sure \\
\hline 3 & Doubtful (between right and wrong) \\
\hline 4 & Almost certain \\
\hline 5 & Certain \\
\hline
\end{tabular}

Tabel 2. Profil konsepsi berdasarkan CRI dan jawaban siswa

\begin{tabular}{cll}
\hline $\begin{array}{c}\text { Kriteria } \\
\text { Jawaban } \\
\text { Siswa }\end{array}$ & CRI rendah $(<\mathbf{3 , 5 )}$ & $\begin{array}{c}\text { CRI tinggi }(> \\
\mathbf{3 , 5})\end{array}$ \\
\hline Jawaban & Tidak memahami & Memahami \\
Benar & konsep (menebak) & $\begin{array}{l}\text { konsep } \\
\text { dengan baik }\end{array}$ \\
\hline
\end{tabular}

\begin{tabular}{ccc}
\hline $\begin{array}{c}\text { Kriteria } \\
\text { Jawaban } \\
\text { Siswa }\end{array}$ & CRI rendah $(<\mathbf{3 , 5 )}$ & $\begin{array}{c}\text { CRI tinggi }(> \\
\mathbf{3 , 5})\end{array}$ \\
\hline $\begin{array}{c}\text { Jawaban } \\
\text { Salah }\end{array}$ & Tidak memahami & \multirow{2}{*}{ Miskonsepsi } \\
\hline
\end{tabular}

Efektivitas media diukur dengan menggunakan tes tulis (pre-test dan posttest) dan dianalisis menggunakan uji $\mathrm{N}$-gain (Hartini et al. 2017), dengan persamaan:

$$
\langle g\rangle=\frac{\left(\% S_{i}-\% S_{f}\right)}{\left(\% S_{m a k s i}-\% S_{f}\right)}
$$

(Hake, 1999)

$\langle g\rangle=$ Penurunan miskonsepsi siswa

$\%\left\langle S_{i}\right\rangle=$ Miskonsepsi siswa pada pretes

$\%\left\langle S_{f}\right\rangle=$ Miskonsepsi siswa pada postes $\%\left\langle S_{m a k s}\right\rangle=$ Persentase maksimal

Nilai $N$-gain digunakan untuk menentukan kategori efektifitas ebook.

Tabel 3. Kategori efektifitas ebook

\begin{tabular}{cc}
\hline$\langle\boldsymbol{g}\rangle$ & Kategori \\
\hline $\mathbf{g}>\mathbf{0 , 7}$ & Sangat efektif \\
\hline $\mathbf{0 , 3}<\mathbf{g} \leq \mathbf{0 , 7}$ & Efektif \\
\hline $\mathbf{g} \leq \mathbf{0 , 3}$ & Kurang efektif \\
\hline & Dimodifikasi dari Hake (1999).
\end{tabular}

\section{E. Tahap Evaluasi}

Siswa diminta memberikan respons terkait ebook yang dikembangkan sebagai evaluasi ebook serta mengukur tingkat kepraktisan ebook (Hartini et al., 2017).

Tabel 4. Kategori kepraktisan ebook

\begin{tabular}{cc}
\hline Persentase (\%) & Kategori \\
\hline $0-20$ & Sangat lemah \\
\hline $21-40$ & Lemah \\
\hline $41-60$ & Cukup \\
\hline $61-80$ & Praktis \\
\hline $81-100$ & Sangat Praktis \\
\hline & (Hartini et al. 2017)
\end{tabular}

\section{HASIL DAN PEMBAHASAN}

Model Instructional Design Strategy yang dikembangkan oleh Moore \& Kearsley (2012) terlaksana secara utuh pada penelitian ini tanpa ada komponen yang dihilangkan. Literatur instrumen validasi harus sesuai standar serta validator harus benar-benar pakar di bidangnya (Sullivan, 2012). Maka 
dari itu, instrumen validasi ebook menggunakan Instrumen Penilaian Buku Teks Pelajaran Kurikulum 2013 Fisika Sekolah Menengah Atas: Buku Siswa, oleh Badan Nasional Standar Pendidikan atau BNSP pada tahun 2014. Validator terdiri atas tiga dosen ahli, yaitu ahli materi, media, dan bahasa serta tiga orang guru fisika dengan kualifikasi pendidikan magister.

Tabel 5. Hasil validasi materi ebook

\begin{tabular}{lcc}
\hline \multicolumn{1}{c}{ Indikator } & Rata-rata & Kategori \\
\hline $\begin{array}{l}\text { Dimensi sikap } \\
\text { spiritual }\end{array}$ & $82 \%$ & Sangat layak \\
\hline $\begin{array}{l}\text { Dimensi Sikap Sosial } \\
\text { (KI 2) }\end{array}$ & $87 \%$ & Sangat layak \\
\hline $\begin{array}{l}\text { Dimensi Pengetahuan } \\
\text { (KI 3) Cakupan } \\
\text { Materi }\end{array}$ & $89 \%$ & Sangat layak \\
\hline $\begin{array}{l}\text { Dimensi Pengetahuan } \\
\text { (KI 3) Akurasi Materi }\end{array}$ & $89 \%$ & Sangat layak \\
\hline $\begin{array}{l}\text { Dimensi Pengetahuan } \\
\text { (KI 3) Kemutakhiran } \\
\text { dan kontekstual }\end{array}$ & $88 \%$ & Sangat layak \\
\hline $\begin{array}{l}\text { Dimensi } \\
\text { Keterampilan (KI 4) } \\
\text { Kemutakhiran dan } \\
\text { kontekstual }\end{array}$ & $90 \%$ & Sangat layak \\
\hline Rata-rata & $\mathbf{8 7 \%}$ & Sangat layak \\
\hline
\end{tabular}

Tabel 6. Hasil validasi media ebook

\begin{tabular}{lcc}
\hline \multicolumn{1}{c}{ Indikator } & Rata-rata & Kategori \\
\hline $\begin{array}{l}\text { Teknik } \\
\text { penyajian }\end{array}$ & $88 \%$ & Sangat layak \\
\hline $\begin{array}{l}\text { Pendukung } \\
\text { penyajian materi }\end{array}$ & $85 \%$ & Sangat layak \\
\hline $\begin{array}{l}\text { Penyajian } \\
\text { Pembelajaran }\end{array}$ & $84 \%$ & Sangat layak \\
\hline Rata-rata & $85 \%$ & Sangat layak \\
\hline
\end{tabular}

Tabel 7. Hasil validasi kebahasaan ebook

\begin{tabular}{lcc}
\hline \multicolumn{1}{c}{ Indikator } & Rata-rata & Kategori \\
\hline $\begin{array}{l}\text { Sesuai dengan } \\
\text { perkembangan } \\
\text { peserta didik }\end{array}$ & $82 \%$ & Sangat layak \\
\hline Komunikatif & $86 \%$ & Sangat layak \\
\hline $\begin{array}{l}\text { Dialogis dan } \\
\text { interaktif }\end{array}$ & $86 \%$ & Sangat layak \\
\hline $\begin{array}{l}\text { Koherensi dan } \\
\text { keruntutan alur } \\
\text { pikir }\end{array}$ & $84 \%$ & Sangat layak \\
\hline $\begin{array}{l}\text { Kesesuaian dengan } \\
\text { kaidah Bahasa }\end{array}$ & $85 \%$ & Sangat layak \\
Indonesia & $83 \%$ & Sangat layak \\
\hline $\begin{array}{l}\text { Penggunaan istilah } \\
\text { dan } \\
\text { simbol/lambang }\end{array}$ & $84 \%$ & Sangat layak \\
\hline Rata-rata & & \\
\hline
\end{tabular}

Hasil validasi ebook secara rata-rata dari segi materi, media, dan bahasa dapat ditinjau pada Tabel 9.

Tabel 8. Hasil Validasi ebook

\begin{tabular}{llll}
\hline No & Kriteria & Persentase & Kategori \\
\hline 1 & Materi & $87,0 \%$ & Sangat layak \\
\hline 2 & Media & $85,0 \%$ & Sangat layak \\
\hline 3 & Bahasa & $84,0 \%$ & Sangat layak \\
\hline & Rata-rata & $85,3 \%$ & Sangat layak \\
\hline
\end{tabular}

Hasil validasi oleh tiga dosen ahli dan tiga guru fisika memperoleh skor rata-rata $85,3 \%$ dengan kategori sangat layak. Artinya, ebook yang dikembangkan telah sesuai dengan aturan BNSP dan siap untuk digunakan untuk siswa di Indonesia dalam pembelajaran fisika pada materi rangkaian listrik.

Keefektifan media diukur berdasarkan penurunan miskonsepsi siswa. Penurunan miskonsepsi siswa pada tiap butir soal dapat dilihat pada Gambar 3.

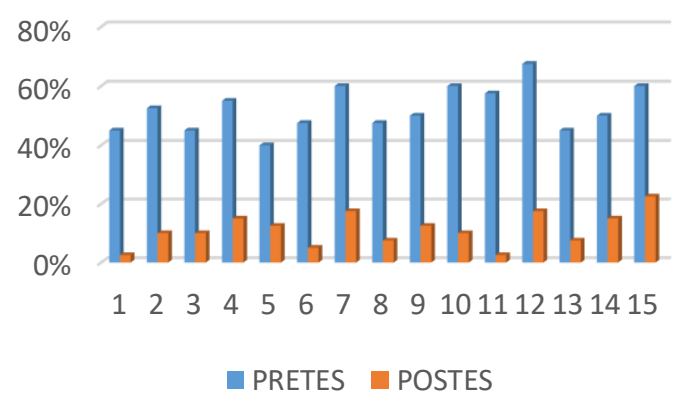

Gambar 1. Grafik penurunan miskonsepsi siswa

Berdasarkan grafik tersebut, miskonsepsi materi listrik dinamis ditemukan pada saat pretes maupun postes, namun terjadi penurunan persentase miskonsepsi pada setiap soal. Pada soal nomor 1 miskonsepsi siswa saat pretes sangat tinggi karena siswa menganggap pada rangkaian seri, lampu yang paling dekat dengan kutub positif dari sumber tegangan mendapatkan kuat arus yang paling banyak sehingga komponen selanjutnya mendapatkan kuat arus dari sisa komponen sebelumnya. Praktikum dengan perangkat 
lunak $\mathrm{PhET}$ dan petunjuk lengkap pada ebook mampu menurunkan miskonsepsi sekitar $43 \%$.

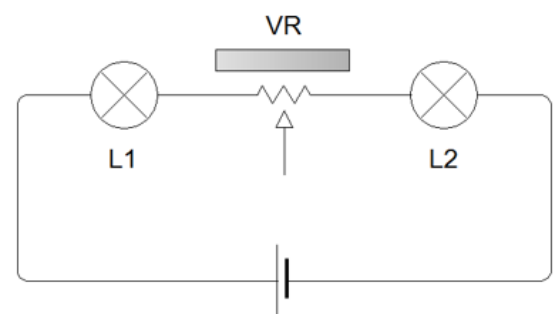

Gambar 2. Soal nomor 2-4

Soal nomor 2 hingga 4 berkaitan dengan pengaruh potensiometer VR terhadap komponen pada rangkaian. Saat pretes kebanyakan siswa menganggap lampu L1 menerima kuat arus paling tinggi dan paling dahulu sehingga tidak ada pengaruh saat potensiometer VR diperbesar atau diperkecil. Namun, miskonsepsi tersebut dapat dikurangi dengan praktikum rangkaian seri menggunakan perangkat lunak PhET dengan petunjuk rinci pada ebook, siswa merasakan pengalaman langsung pengaruh naik turunnya hambatan VR terhadap komponen pada rangkaian.

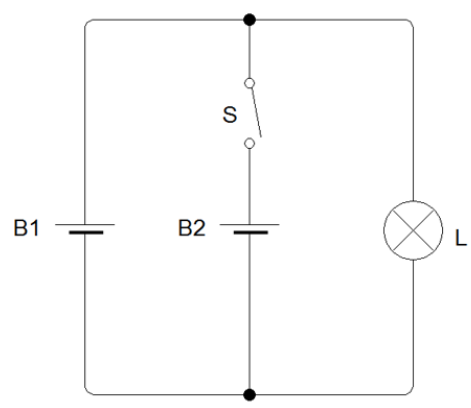

Gambar 3. Soal nomor 5-7

Pada soal nomor 5-7, menganalisis pengaruh penambahan sumber tegangan yang dirangkai paralel terhadap lampu L1. Terlihat dari pretes, siswa menganggap saat saklar pada posisi ON, lampu akan menyala lebih terang. Praktikum menggunakan perangkat lunak PhET berhasil membantu siswa untuk mengurangi miskonsepsi, dengan petunjuk pada ebook, siswa mengukur kuat arus yang melewati lampu serta tegangan pada lampu untuk dengan saksama untuk membuktikan pengaruh baterai yang dirangkai paralel terhadap lampu.

Pada soal nomor 8-9, siswa menganalisis perubahan yang terjadi pada lampu yang dipasang paralel, apabila salah satunya dicabut. Siswa menganggap dicabutnya salah satu akan membuat lampu lain menyala lebih terang serta beda potensialnya meningkat. Namun, logika mereka yang salah dapat dikurangi dengan praktikum rangkaian paralel melalui perangkat lunak PhET sesuai petunjuk yang ada pada ebook. Hasilnya, dengan melakukan pengukuran serta pengamatan mandiri, siswa mengetahui kesalahan konsepnya yang terbukti dari turunnya miskonsepsi pada soal nomor 8-9.

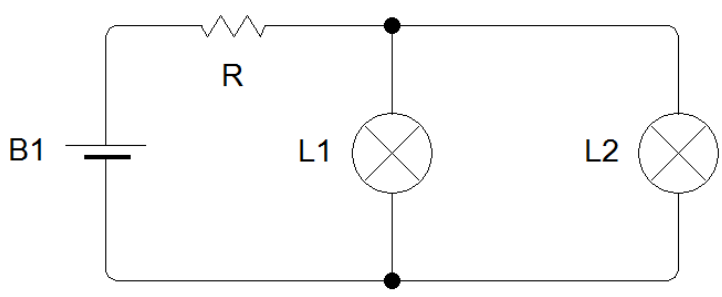

Gambar 4. Soal nomor 10

Soal nomor 10 adalah aplikasi penguasaan konsep lanjutan, pengaruh dicabutnya salah satu lampu terhadap lampu yang lain. Saat pretes, siswa masih menganggap dicabutnya lampu L2 tidak memberikan pengaruh pada kuat arus yang melewati lampu L1. Karena siswa sudah melakukan praktikum ini menggunakan PhET sesuai petunjuk, miskonsepsi dapat turun.

Pada soal nomor 11 dan 12, tentang pengaruh penambahan hambatan pada rangkaian seri terhadap komponen lain. Saat pretes, siswa menganggap apapun yang terjadi, tidak ada pengaruh penambahan resistor terhadap besar kuat arus dan tegangan komponen lain pada rangkaian seri. Namun praktikum PhET melalui pengukuran besar kuat arus dan tegangan pada resistor mampu membuat siswa memahami 
kesalahan tersebut dengan menjawab tepat saat post-test.
(1)

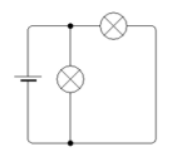

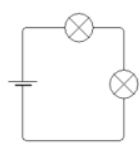

(2)

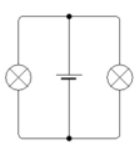

(3)

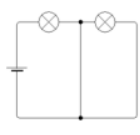

(4)
Gambar 5. Soal nomor 13

Pada soal nomor 13, siswa diharuskan memilih rangkaian mana yang termasuk rangkaian paralel. Saat pretes, siswa menganggap rangkaian 4 juga termasuk rangkaian paralel, padahal saat posisi ON, akan terjadi arus pendek pada rangkaian tersebut.

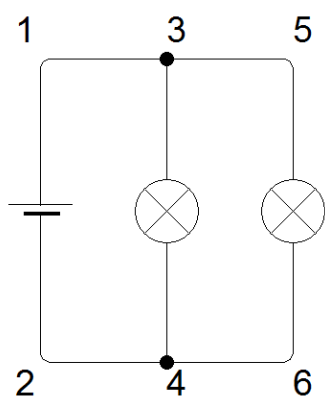

Gambar 6. Soal nomor 14

Pada soal nomor 14 , saat pretes siswa menganggap titik terdekat dari kutub positif rangkaian listrik adalah yang mendapatkan kuat arus listrik terbesar sehingga jawaban mereka berujung pada miskonsepsi, nomor 1 , 3 , dan 5 secara berturut-urut adalah titik yang mendapatkan kuat arus listrik terbesar.

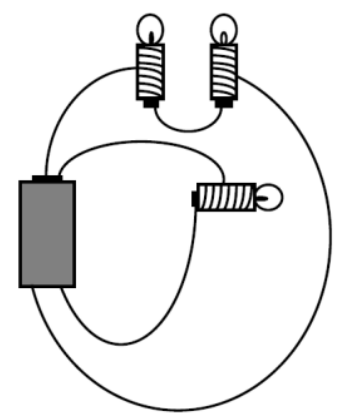

Gambar 7. Soal nomor 15

Pada soal nomor 15 , siswa memilih sketsa gambar manakah yang sesuai dengan rangkaian di atas. Kebanyakan siswa bingung mengenai kabel yang dipasang tidak konsisten pada lampu memberikan efek khusus pada nyala lampu sehingga mereka menjawab dengan jawaban yang salah. Dengan praktikum menggunakan PhET, siswa mengetahui jawaban mereka tentang hal tersebut, sehingga miskonsepsi turun dengan taraf sedang.

Tabel 9. Hasil tes

\begin{tabular}{cccc}
\hline $\begin{array}{c}\text { Persentase } \\
\text { miskonsepsi } \\
\text { Pretes }\end{array}$ & $\begin{array}{c}\text { Persentase } \\
\text { miskonsepsi } \\
\text { Postes }\end{array}$ & N-gain & Kategori \\
\hline $52 \%$ & $11 \%$ & 0,46 & Efektif \\
\hline
\end{tabular}

Praktik menggunakan media simulasi merupakan solusi yang mungkin untuk membuat pengetahuan abstrak menjadi konkret di kelas. Kegiatan menggunakan perangkat lunak simulasi penting karena merangsang minat siswa dalam pembelajaran kelas, membantu memvisualisasikan pengetahuan, dan meminimalkan kesulitan yang biasanya ditemukan dalam pembelajaran (Fiscarellia et al. 2013). Penguatan pembelajaran melalui buku ajar, media, dengan metode pembelajaran yang tepat akan mendapatkan kualitas pemahaman yang lebih tinggi. Belajar disertai sejumlah aktivitas langsung menghasilkan retensi hingga 90\%, semakin banyak kesempatan, siswa belajar semakin banyak. Isi dari buku harus memberikan siswa kesempatan belajar mandiri, melimpahkan banyak waktu untuk aktivitas siswa, sehingga secara otomatis siswa belajar (Alós \& Lago, 2012). Ebook yang dikembangkan mengajak siswa melakukan sejumlah kegiatan mandiri untuk memperbaiki miskonsepsinya melalui perangkat lunak $\mathrm{PhET}$. Hasilnya berdasarkan uji $\mathrm{N}$-gain dengan skor 0,42, maka pembelajaran menggunakan ebook interaktif disertai perangkat lunak PhET mampu menurunkan miskonsepsi siswa dalam kategori efektif.

Kepraktisan ebook diperoleh dari angket respons siswa. siswa sebagai pengguna ebook. Aspek kepraktisan diukur berdasarkan dengan aspek kejelasan format, 
materi, media, dan kebahasaan ebook (Hartini et al. 2017).

Tabel 10. Kategori ebook

\begin{tabular}{cc}
\hline Kriteria & Persentase \\
\hline Materi & $92,97 \%$ \\
\hline Media & $90,63 \%$ \\
\hline Bahasa & $94 \%$ \\
\hline Rata-rata & $92,53 \%$ \\
\hline
\end{tabular}

Kepraktisan diukur dengan: Aspek materi: 1) Kemudahan siswa dalam memahami materi dan ilustrasi; dan 2) Kesesuaian materi yang disajikan ebook. Aspek media: 1) Kemampuan ebook untuk membangkitkan motivasi belajar siswa; dan 2) Kemenarikan ebook. Aspek Bahasa; 1) Bahasa ebook mudah dipahami atau tidak? dan 2) Kemudahan dalam memahami istilah dalam ebook. Hasil analisis kepraktisan ebook mendapatkan rata-rata skor $92,53 \%$ dengan kategori sangat praktis. Perangkat lunak dan media pembelajaran yang menampilkan animasi, grafik, interaktivitas yang sesuai mampu mendorong partisipasi dan keterlibatan siswa dalam kegiatan pembelajaran aktif serta secara efektif menjelaskan dan mengilustrasikan topik kursus, dan untuk membangun keterampilan pemecahan masalah siswa (Carbonell et al, 2013).

Dalam setiap sub topik pada ebook selalu disajikan kuis untuk mengetahui tingkat pemahaman siswa. Jika siswa masih mendapatkan nilai di bawah KKM, mereka masih dapat mengulanginya kembali sampai hasil yang didapatkan maksimal dan mendapatkan stiker bergambar khusus sebagai feedback. Kuis yang disertai umpan balik berfungsi sebagai motivator siswa untuk belajar dan sebagai alat ukur bagi guru tentang tingkat penguasaan materi yang telah diajarkan sebelumnya (Elihami, 2016). Siswa cenderung meningkatkan belajarnya jika ada tes di akhir pembelajaran. Idealnya, mereka mengupayakan secara penuh untuk mempelajari materi yang diperkirakan muncul dalam tes. Dalam kasus penelitian ini, bahan yang dibuat evaluasi postes sudah dipelajari secara penuh dalam kuis ebook dan praktik. Dengan begitu, apa yang diajarkan tepat sasaran. Laboratorium virtual yang dikombinasikan dengan model pembelajaran yang tepat dapat meningkatkan penguasaan konsep peserta didik (Hermansyah et al. 2017).

Dalam eksperimen nyata sangatlah sulit membuat sumber tegangan ideal, kemungkinan terjadi kesalahan dalam rangkaian hingga terjadi kerusakan komponen sangat mungkin terjadi, lebih parahnya tentu bisa menambah rintangan terhadap konsep pemahaman. Pada simulasi $\mathrm{PhET}$, kesalahan-kesalahan apapun dalam merangkai tidak akan berpengaruh. Penggunaan PhET dalam pembelajaran atau eksperimen meningkatkan efisiensi pembelajaran. Petunjuk berbasis komputer dalam bentuk ebook yang menarik dan praktikum dengan simulasi komputer untuk menyederhanakan pelajaran yang relevan dikembangkan mampu untuk peningkatan pencapaian hasil belajar yang lebih tinggi (Krobthong, 2015).

\section{PENUTUP}

Model Instructional Design Strategy yang dikembangkan oleh Moore \& Kearsley (2012) terlaksana secara utuh pada penelitian ini. Ebook listrik dinamis layak digunakan dalam pembelajaran fisika materi listrik dinamis. Hal ini berdasarkan validitas dengan kategori sangat layak, efektivitas ebook dengan kategori efektif, dan kepraktisan dengan kategori sangat praktis. Perlu dikembangkan ebook dengan model lain agar miskonsepsi siswa dapat turun dengan kategori sangat efektif.

\section{REFERENSI}

Adams, W.K., 2010. Student engagement and learning with PhET interactive simulations. Il Nuovo Cimento, 33 (3), 21-32. 
Alós, P \& Lago, R., 2012. Ebook, An Innovative Tool Towards the TeachingLearning Process. Huelva: Department of Psychology and Education. University of Huelva (Spain).

Carbonell, V., Romero, C., Martínez, E., \& Flórez, M., 2013. Interactive simulations as teaching tools for engineering mechanics courses. European Journal of Physics, 34 (4), 991-1004.

Cranmer, G. A., 2017. One-group pretestposttest design. In The SAGE Encyclopedia of Communication Research Methods (p. 1126).

Darlen, R.F., Sjarkawi, dan Lukman, A., 2015. Pengembangan E-Book Interaktif untuk Pembelajaran Fisika SMP. Jurnal Tekno-Pedagogi, 5 (1), 13-23.

Dingli, A. dan Cachia, C., 2014. Adaptive eBook. In: 2014 International Conference on Interactive Mobile Communication Technologies and Learning (IMCL2014). IEEE, 14-19.

Elihami, E., 2016. Meningkatkan Hasil Belajar Al-Islam Dan Kemuhammadiyahan Melalui Kuis Dengan Umpan Balik Pada Mahasiswa. SAFINA Jurnal Pendidikan Agama Islam, 1 (2), 27-37.

Engelhardt, P. \& Beichner, R., 2013. Determining and Interpreting Resistive Electric Circuit Concepts Test (DIRECT). Supporting physics teaching with research-based resources. PhysPort.

Fajar, D., M. \& Supardi, Z. A. I., 2013. Pengaruh Penggunaan Model Pembelajaran Inkuiri (Inquiry Learning) Terhadap Penurunan Miskonsepsi Pada Materi Listrik Dinamis Kelas X SMAN 2 Jombang. Jurnal Inovasi Pendidikan Fisika (JIPF), 2 (2), 24-29.

Fiscarellia, S. H., Bizelli, M. H. S. S., \& Fiscarelli, P. E., 2013. Interactive Simulations to Physics Teaching: A Case Study in Brazilian High School. International Journal of Learning and
Teaching, 5(1), 18-23.

Hackathorn, J., Solomon, E.D., Blankmeyer, K.L., Tennial, R.E., dan Garczynski, A.M., 2011. Learning by Doing: An Empirical Study of Active Teaching Techniques. The Journal of Effective Teaching, 11 (2), 40-54.

Hartini, S., Misbah, Dewantara, D., Oktovian, R.A., dan Aisyah, N., 2017. Developing learning media using online prezi into materials about optical equipments. Jurnal Pendidikan IPA Indonesia, 6 (2), 313-317.

Hartono, Sunarno, W., Sarwanto, dan Nugraha, D.A., 2017. Analysis of critical thinking ability in direct current electrical problems solving. Journal of Physics: Conference Series, 909 (1), 012061.

Hasan, S., Bagayoko, D., \& Kelley, E. L., 1999. Misconceptions and the Certainty of Response Index (CRI). Physics Education, 34(5), 294-299.

Hermansyah, Gunawan, Harjono, A., 2017. Pengaruh Penggunaan Laboratoium Virtual dalam Pembelajaran Inkuiri Terbimbing Terhadap Penguasaan Konsep Kalor Peserta Didik. Jurnal Pendidikan Fisika dan Teknologi, 3 (2), 249-256.

Sugiana, I. N., Harjono, A., Sahidu, H., \& Gunawan. 2016. Pengaruh Model Pembelajaran Generatif Berbantuan Media Laboratorium Virtual Terhadap Penguasaan Konsep Fisika Siswa pada Materi Momentum dan Impuls. Jurnal Pendidikan Fisika dan Teknologi, 2(2), 61-65.

Hidayatulloh, M., Humairoh, F., Wachidah, U., Iswati. D. A., \& Suliyanah., 2015. Pengembangan Perangkat Pembelajaran untuk Mereduksi Miskonsepsi Siswa pada Materi Rangkaian Listrik dengan Scientific Approach. Jurnal Penelitian Fisika dan Aplikasinya (JPFA), 5 (1), 28-32.

Ismail, I. I., Samsudin, A., Suhendi, E., dan Kaniawati, I., 2015. Diagnostik Miskonsepsi Melalui Listrik Dinamis 
Four Tier Test. Prosiding Simposium Nasional Inovasi dan Pembelajaran Sains, 2015 (SNIPS), 381-384.

Istifarida, B., Sigit, S., \& Yasin, Y., 2017. "Pengembangan ebook Berbasis Problem Based Learning-GIS Untuk Peningkatan Kecakapan Berfikir Keruangan Pada Siswa Kelas X SMAN 1 Sragen 2016/2017”. Jurnal GeoEco. 3 (2), 133- 144.

Krobthong, T., 2015. Teaching University Physics by Using Interactive Science Simulations Methods. Procedia - Social and Behavioral Sciences, 197, 18111817.

Lidiana, H., Gunawan., \& Taufik, M., 2018. Pengaruh Model Discovery Learning Berbantuan Media PhET terhadap Hasil Belajar Fisika Peserta Didik Kelas XI SMAN 1 Kediri Tahun Ajaran 2017/2018. Jurnal Pendidikan Fisika dan Teknologi, 4 (1), 33-39.

Moore, G.M. \& Kearsley, G., 2012. Distance Education: a System View of Online Learning. Third Edition. Belmont, CA: Wadswoth, Cengage Learning.

Niami, K., Kosim., Gunawan., 2018. Model Problem Based Learning Berbantuan Simulasi Komputer Untuk Meningkatkan Penguasaan Konsep Pada Materi Alat-Alat Optik. Jurnal Pendidikan Fisika dan Teknologi. 4 (2), 220-225.

Pitterson, N. P., \& Streveler, R. A., 2016. Teaching and learning complex circuit concepts: An investigation of the intersection of prior knowledge, learning activities, and design of learning environments. In ASEE Annual Conference and Exposition, Conference Proceedings (Vol. 2016-June).

Quezada, E. M., del Campo, V., \& Zavala, G., 2015. Technology and researchbased strategies: Learning and alternative conceptions. In 2015 Physics Education Research Conference Proceedings (pp. 271-274).

Rusilowati, A. 2006. Profil kesulitan belajar fisika pokok bahasan kelistrikan siswa SMA di kota Semarang. Jurnal Pendidikan Fisika Indonesia, 4(2), 100 106.

Sihombing, Y. \& Novitasari, I., 2017. Deskripsi Kesulitan Belajar Peserta Didik dan Faktor Penyebabnya dalam Memahami Materi Listrik Dinamis Kelas X SMA Negeri 2 Bengkayang. Jurnal Penelitian Fisika dan Aplikasinya (JPFA), 07 (01) 44-53.

Sullivan, G. M., 2011. A Primer on the Validity of Assessment Instruments. Journal of Graduate Medical Education, June 199-200.

Suryaman, M., 2015. Analisis Hasil Belajar Peserta Didik Dalam Literasi Membaca Melalui Studi Internasional (Pirls) 2011. Litera, 14 (1), 170-186.

Turgut, U., Gurbuz, F., \& Turgut, G., 2012. 10 th grade science class students' misconceptions about electric current. Energy Education Science and Technology Part B: Social and Educational Studies, 4(2), 627-636.

Yulianci, S., Gunawan, \& Doyan, A., 2017. Model Inkuiri Terbimbing Berbantuan Multimedia Interaktif untuk Meningkatkan Penguasaan Konsep Fisika Peserta Didik. Jurnal Pendidikan Fisika dan Teknologi. 3 (2) 146-154.

Zuhri, M. S. \& Jatmiko, B., 2014. Penerapan Model Pembelajaran Inkuiri (Inquiry Learning) Menggunakan PhET Simulation Untuk Menurunkan Miskonsepsi Siswa Kelas XI pada Materi Fluida Statis di SMAN Kesamben Jombang. Jurnal Inovasi Pendidikan Fisika (JIPF), 3, (3), 103107. 